\title{
De la exclusión a la heteronomía. Inmigrantes en la ficción televisiva Aída
}

\section{From exclusion to heteronomy. Immigrants in television fiction Aída}

\author{
Laetitia Biscarrat
}

Doctora en Ciencias de la Comunicación (Universidad de Bordeaux 3)

\section{Natalia Meléndez Malavé}

Profesora ayudante doctora (Departamento de Periodismo de la Facultad de Ciencias de la Comunicación de la Universidad de Málaga)

Fecha de recepción: 8 de septiembre de 2013

Fecha de revisión: 24 de octubre de 2013

Para citar este artículo: Biscarrat, Laetitia y Meléndez Malavé, Natalia (2014): De la exclusión a la heteronomía. Inmigrantes en la ficción televisiva Aída, Icono 14, volumen (12), pp. 319-346. doi: 10.7195/ri14.v12i1.566 


\section{Resumen}

En fechas recientes el aumento de la inmigración en España ha favorecido una mayor visibilidad en todos los niveles de la sociedad, también en el ámbito de la ficción televisiva. Es justamente en ese contexto en el que fue estrenada por Tele5 la comedia de situación Aída. Consideramos este producto un punto de vista privilegiado para la indagación acerca de las representaciones e imaginarios sociales que acompañan al fenómeno migratorio. En este trabajo se aborda la evolución en el tratamiento que se le ha dispensado, con un corpus que recorre ocho temporadas de la telecomedia, entre 2005 y 2011. El objetivo es doble: por una parte, identificar los estereotipos etno-raciales $y$, por otra, estimar su intensidad ajustándonos a una escala que describe distintos grados. Al término de la medición diacrónica de la intensidad de dicha estereotipación, podemos afirmar que se dibuja una evolución a lo largo de las temporadas, pero que esta evolución no es estrictamente lineal.

\section{Palabras clave}

Televisión - Inmigración - Ficción - Serie - Estereotipos - Imaginario - Extranjero

\section{Abstract}

Lately, the increasing rate of migrants in Spain has triggered their increased visibility in every sphere of society, including TV dramas. The community soap Aida which is broadcasted on Tele5 was created in this context. We consider TV fiction as a privileged standpoint to focus on media representations and social imaginaries linked to the migratory topic. Thus, this article deals with the evolution of migrants' representations between 2005 and 2011, in other words 8 seasons of the community soap. We aim both at identifying racial stereotypes and measuring their intensity according to a qualitative scale. Eventually, this diachronic analysis of stereotypes reveals an evolution but it can't be considered as a strict improvement.

\section{Key Words}

Television - Immigration - Fiction - Series - Stereotypes - Imaginary - Foreigner 


\section{Introducción}

Tradicionalmente tierra de emigrantes, la sociedad española ha debido adaptarse a su nuevo perfil como territorio de acogida, pues el país ha conocido en los últimos treinta años un aumento masivo del flujo de población inmigrante. Según el censo de 2011, los extranjeros representan el 14,1\% de los cerca de 47 millones de habitantes (INE, 2011). El mosaico de la inmigración en España se caracteriza por la presencia de población procedente de áreas próximas geográfica o culturalmente. Así, la mayoría proviene de Iberoamérica, con un 36,21\% del total de extranjeros establecidos en España, seguidos de los procedentes de países de la Unión Europea $(34,45 \%)$ y del Norte de África $(14,83 \%)$. (INE, 2011).

La prosperidad económica que caracterizó al país hasta 2009 y el consiguiente crecimiento del número de inmigrantes han favorecido una mayor visibilidad de estos últimos en todos los niveles de la sociedad. Es justamente en ese contexto en el que fue estrenada en 2005 en el canal privado generalista Tele5 la comedia de situación Aída.

Esta serie constituye el primer caso de spin-off español: su protagonista, una mujer divorciada que busca educar lo mejor que puede a dos hijos conflictivos, aparecía ya como una limpiadora alcohólica en la teleserie 7 vidas. En esta ocasión, Aída García se instala con su madre, Eugenia, su hermano Luisma y sus hijos adolescentes en el humilde barrio de Esperanza Sur. La serie relata, pues, la vida cotidiana de esta familia y su relación con los vecinos del barrio, cosechando un gran éxito de público. Emitida en prime-time desde el 16 de enero de 2005, ha obtenido a lo largo de sus ocho primeras temporadas una audiencia media de entre 3 y 5 millones de espectadores, según la cadena. Este seguimiento ha tenido su continuidad y mientras se emite la novena temporada ya está en preparación la décima.

Tanto por su audiencia como por su calado en el acervo cultural español (identificación con los personajes, acogida de los giros lingüísticos, etc.), Aída ocupa un lugar destacado en la producción televisiva nacional. Es por este motivo por el que la consideramos un punto de vista privilegiado para la observación e indagación acerca de las representaciones e imaginarios sociales que acompañan al fenómeno 
migratorio. En efecto, dicho fenómeno migratorio no existe por sí mismo, de manera autónoma, sino a través de una coproducción de significaciones producidas por varias tecnologías, sociales, políticas y, en el caso que nos interesa, mediáticas. Así, hacemos nuestra la aserción de Xavier Ruiz Collantes: “La premisa fundamental del trabajo parte de la consideración de la importancia de la ficción televisiva en los procesos de creación de imaginarios y prototipos sociales que influyen en la forma en que el público percibe, piensa y vive la realidad social, lo cual afectaría decisivamente a la construcción de una imagen pública del inmigrante, así como de las problemáticas derivadas de los procesos de inmigración" (Collantes, 2006: 94). En otros términos, la realidad tal como está percibida y experimentada está coproducida por los medios. El paradigma de las "mediaculturas" desarrollado por los sociólogos de los medios franceses Eric Maigret y Eric Macé analiza este fenómeno subrayando las tres características fundamentales de la esfera mediática. Se trata a la vez de una palestra en la que se escenifican las dinámicas públicas y de un recurso cultural para las audiencias ya que nos enseña una gran parte de las cosas que sabemos del mundo; también es una escena performativa "porque no es la representación de una realidad pre-existente, sino la muestra de un punto de vista, la puesta en escena de un enfoque interpretativo, la propuesta de una legitimación o destabilización mas o menos importante de lo esperado" (Macé, 2007:10)1. Así pues, las representaciones televisivas no reflejan una realidad pre-existente a la producción mediática sino un conformismo provisorio. Ilustran cómo una determinada sociedad se representa a sí misma a través de sus compromisos, sus ideales, sus imaginarios, sus silencios. Desde este punto de partida, la perspectiva adoptada en la presente investigación considera las representaciones televisivas como un campo de exploración social. Se trata de una experiencia mediática del mundo que nos rodea. En otras palabras, las representaciones mediáticas de la televisión no son el reflejo de una realidad social. Más bien, contraponemos a esa percepción mimética del funcionamiento de los medios una aproximación constructivista. Los medios restituyen una proyección del campo de las representaciones sociales sometida a su mediación. Asimismo, en lugar de un análisis clásico de la representación de los inmigrantes en la serie, hemos optado por interrogarnos acerca de la evolución en el tratamiento que se ha hecho de este aspecto a lo largo de la serie entre $2005 \mathrm{y}$ 2011. Esta perspectiva diacrónica recorre ocho temporadas de la telecomedia, con el trasfondo de los vaivenes de la sociedad española entre una relativa prosperidad 
y una importante crisis económica y social. El objetivo es doble. Por un lado, se trata de localizar la presencia de estereotipos de los inmigrantes en la ficción. Por otro lado, queremos medir la evolución de este proceso de estereotipación a través de una perspectiva diacrónica. Este primer nivel de análisis nos permitirá entender el fenómeno de coproducción mediática de la comunidad nacional española en una serie destacada por sus imaginarios de la vida cotidiana de gente "como nosotros". En resumen, la investigación ambiciona destacar el papel de una ficción televisiva como tecnología social (Foucault, 1976).

En España, la investigación sobre medios e inmigración se organiza en dos ramas principales (Igartua Perosanz et al., 2011). La primera rama coincide con los trabajos sobre el tratamiento informativo de la inmigración y sus efectos socio-cognitivos. Por ejemplo, se destacan precisamente los estudios de Juan José Igartua y otros (2005 y 2007) sobre el tratamiento de la inmigración en la prensa informativa. La segunda rama, más escasa, se centra en el tratamiento de los inmigrantes en la ficción televisiva. Aunque este género forma una parte central de la programación televisiva, estos trabajos continúan siendo bastante escasos, como subraya Juan José Igartua: “En España son prácticamente inexistentes los trabajos empíricos en torno al tratamiento de la inmigración en la ficción televisiva" (Igartua Perosanz et al., 2011: 221). Es relevante que esta investigación haya sido realizada dentro de un programa de investigación ajeno con un equipo franco-español. Estas condiciones prácticas influyen en el marco teórico y en la metodología. En efecto, esta perspectiva nos recuerda que los contenidos mediáticos son el producto de una historia y un contexto sociocultural especifico. En ningún caso podemos considerar la ficción televisiva como un objeto cultural inmanente.

Volviendo a la producción científica del país de producción y difusión de la serie, la escasa investigación del campo no obstante evoluciona. Se han realizado en la última década algunos estudios empíricos sobre la representación de la inmigración en la ficción televisiva. Suelen destacar el papel estereotípico que desempeñan los inmigrantes (Galán, 2006; Igartua Perosanz, 2011; Ruiz Collantes, 2006). Además, Charo Lacalle ha realizado un análisis socio-semiótico de la ficción televisiva que constituye una contribución sustancial a este campo de investigación (Lacalle, 2008). Así, nuestra contribución reivindica su pertenencia a esta rama 
de investigación. Esos trabajos destacan la débil presencia de la diversidad en las ficciones y los estereotipos negativos que la acompañan. Esta investigación parte, pues, del siguiente postulado: se presupone la existencia de una presentación estereotipada de los inmigrantes. La serie se caracteriza, en efecto, por recurrir al humor y a la caricatura para satisfacer a un público amplio y familiar. Por otra parte, los estudios precedentes han revelado "una infra-representación de personajes extranjeros-inmigrantes en los programas producidos en España (donde el 76.5\% eran series, comedias de situación o miniseries y el $23.5 \%$ eran largometrajes), ya que en ellos solo aparecen un $7.8 \%$ de extranjeros-inmigrantes, frente al $12.2 \%$ de extranjeros en la sociedad española (INE, 2010)" (Igartua Perosanz, 2011: 226). Este contexto de enunciación televisiva hace, por tanto, esperar la presencia de estereotipos en la serie. Pero, ¿qué población inmigrante es representada?, ¿a qué estereotipos se les asocia? Así pues, se trata de considerar el estereotipo como "un buen indicador de la manera en que los regímenes de presentación participan o no en la legitimación simbólica de la discriminación" (Macé, 2007: 10). La noción de estereotipo se entiende aquí como "la expresión naturalizada de una asimetría de relaciones de poder -poder de nombrar, de mostrar, de reducir, de asignar" (Macé, 2007: 10). Esta definición remite a las investigaciones efectuadas en el marco de los Postcolonial Studies, especialmente tomando como referencia a Albert Memmi, Richard Dyer y Elsa Dorlin. “Los estereotipos no son forzosamente convicciones conscientemente asumidas, sino que pueden ser 'estructuras implícitas de conocimiento' o 'esquemas' que nuestro entorno social implanta en nosotros. Una vez absorbidos, los estereotipos funcionan como expectativas implícitas, las cuales ejercen una influencia sobre nuestra forma de interpretar la información social, sobre las causas a las cuales atribuimos los acontecimientos y sobre la manera en que esos acontecimientos mismos son codificados y reencontrados ('recuperados') en nuestra memoria" (Hamilton Krieger, 2008: 9). Así, estudiar los estereotipos permite enfocar la ideología subyacente, ya que "la principal esfera de operaciones de los medios es la producción y transformación de ideologías" (Hall, 2003: 89). Distinguiendo entre dos tipos de ideologías racistas, el racismo abierto y el racismo ilativo (Hall, 2003: 91), Stuart Hall destaca el papel fundamental de los medios no solo como una potente fuente de ideas sobre raza, sino como un lugar donde estas ideas están "articuladas, trabajadas, transformadas y elaboradas" (Hall, 2003: $90-1)$. Desde esta perspectiva, estudiar la estereotipación de los inmigrantes en la 
serie nos ofrece una entrada privilegiada en la fábrica televisiva de los imaginarios sociales de los inmigrantes.

\section{Material y métodos}

Como se ha adelantado, el corpus delimitado para este análisis comprende episodios de Aida pertenecientes a ocho temporadas, emitidas entre 2005 y 2011. Dicha selección obedece a un criterio narrativo, optando por capítulos en los que la trama favorece el tratamiento de la temática migratoria. De los 153 episodios totales se ha detectado la presencia de contenido ligado a la inmigración en 36, es decir, el 23,5\% del conjunto. El trabajo de identificación de estereotipos viene acompañado por el propósito de evaluar su evolución a lo largo de las temporadas. Así pues, la ficha de análisis diseñada y cumplimentada por las autoras durante el visionado de los capítulos elegidos para obtener los resultados propuestos en esta investigación se organiza en torno a dos operaciones: por una parte, identificar los estereotipos etno-raciales; por otra, estimar su intensidad sobre una escala de nivel 0 a 3, desde lo implícito (nivel 0) al desempeño de un papel en el relato (nivel 3) pasando por la aparición ideológicamente orientada (nivel 1) y los estereotipos verbales (nivel 2). Este método de análisis está basado en un estudio previo realizado por Jean-Philippe De Oliveira (2011). Analiza las estrategias de legitimación de la homosexualidad de los actores institucionales y políticos en las campañas mediáticas de prevención del SIDA desde una perspectiva diacrónica.

En su estudio sobre los roles de la ficción catalana en la construcción de una identidad nacional, Enric Castelló subraya el papel fundamental de los productos culturales y particularmente de las series de televisión: “dado que la construcción de la nación es un proceso cultural y político en el cual los medios de masas desempeñan un papel central, consideramos que la televisión, y las series en particular, son un espacio fundamental de definición de la nación" (Castelló, 2009: 306). Jugando con los matices entre la invisibilidad de los personajes inmigrantes y de la identificación de estereotipos, la ficha de análisis cualitativo nos permite medir la inserción de estas figuras de alteridad en el ficticio barrio español de Esperanza Sur. ¿Dónde se sitúan las fronteras de esta pequeña comunidad prototípica española?, ¿cuáles son los registros de integración posibles para los inmigrantes? 
Comparando a lo largo de los años y las temporadas de la serie los regimenes de presencia de los inmigrantes, esta investigación plantea la cuestión de las modalidades de contribución televisiva a la construcción de un "imaginario nacional" (Anderson, 1991).

\section{Resultados. Una presentación estigmatizada: La estereotipación de los inmigrantes}

Concluida la identificación de estereotipos en los capítulos elegidos, observamos cinco categorías de personajes mostrados bajo las condiciones del estereotipo, que podemos adscribir a determinado origen geográfico-cultural. Por orden de aparición, distinguimos los personajes "vistos como" latinos, africanos, asiáticos, europeos del Este y árabes.

El grupo de los latinos es el más representado. Lo constituyen principalmente empleados del sector terciario: camareros o empleadas de limpieza. Así pues, el personaje recurrente de Osvaldo, alias Machu Pichu, trabaja al servicio de Mauricio, el propietario del bar Reinols, al que se presenta con un perfil muy poco encomiable, caracterizado por su nostalgia del Franquismo y por su xenofobia, machismo y homofobia. Por su parte, Osvaldo es hacendoso y sumiso a su jefe, dos estereotipos asociados aquí a los latinos. El perfil de Osvaldo, y también de Espléndida -la mujer de la limpieza cubana de Eugenia, la abuela glotona $(5 \times 72)^{2}$ - es, en efecto, el de una mano de obra barata y poco cualificada. Como afirma Mauricio a propósito de sus camareros sudamericanos " $\mathrm{i}$ si les hacemos venir del extranjero es para pagarles menos, vamos, como yo hago con los míos!" (3x31). Mauricio es, pues, un explotador que inflinge penosas condiciones laborales a 0svaldo y éste se ve obligado a satisfacer todas sus exigencias: aunque es camarero, ejerce igualmente la función de fontanero (7x122), de saboteador, cuando Mauricio le encarga destrozar una estatua que homenajea el trabajo de los inmigrantes (8x148) o incluso de gigoló, cuando seduce a Eugenia para servir a los intereses de su patrón (6x88). Completamente explotado -por ejemplo, cuando trabaja 24 horas en el bar, reconvertido en hotel por el desalojo de algunos vecinos tras una plaga de ratas (8x153). Además de someterles a estas duras condiciones de trabajo ilegal, Mauricio trata a sus empleados con violencia tanto verbal como física, golpeándoles en repetidas 
ocasiones. No contento con llamar a Osvaldo con el apodo Machu Pichu, Mauricio adjudica a éste conductas salvajes y creencias primitivas. Ante un cartel luminoso instalado en la fachada de su bar, Mauricio exclama: "si ven esto en su país, se creen que es un dios y le hacen jefe de la tribu" (6x109). Por su parte, Eugenia comete los mismos abusos. Llama a 0svaldo "Mowgli" o "el pequeño salvaje" (6x88).

Además, entre los estereotipos asociados a los latinos, encontramos igualmente el gusto por el baile y por todo aquello relacionado con el folklore. Osvaldo ofrece un poncho tejido por su familia a su jefe que lo acaba usando para limpiar el polvo (8x142). Finalmente, también la sexualidad reproductiva prolífica de 0svaldo se pone de manifiesto: de 7 hijos en la sexta temporada (6x88) pasa a 14 en la octava (8x150).

En cuanto a las mujeres sudamericanas, aparecen ya sea como ardientes y jóvenes seductoras, o como excelentes mujeres de la limpieza -el nombre de Espléndida está escogido con esa intención- pero caracterizadas por su menor atractivo en este caso.

En uno de los episodios, Mauricio sale una noche a un club de salsa donde flirtea con Wendolín, una voluptuosa bailarina. Mauricio se jacta allí de ser "el más grande", dando a entender que los sudamericanos son de baja estatura y añade que está rodeado de "Pocahontas" (7x114). En otra trama, la sensual Cristal se prepara para casarse con Mauricio, al que ha conocido por Internet, mientras mantiene una aventura con el personaje de Luisma. La comunidad se une para evitar la boda (1x13). El matrimonio de conveniencia es vivamente rechazado y Cristal es humillada públicamente sin derecho a responder.

Entre los tres perfiles de inmigrantes en que se encuadra a los latinos, la inmigración profesional ilegal es ampliamente tolerada e incluso fomentada por la economía del barrio. Por el contrario, la perspectiva de un matrimonio mixto es unánimemente rechazada. Cristal es en ese sentido una figura-sanción (Bertini, 2002) que se expone a los límites de su adscripción etno-racial y de género. Si los hombres blancos poseen el usufructo de la sexualidad de las mujeres latinas, no ocurre lo mismo cuando los roles se invierten. La perspectiva de la mezcla es igualmente 
rechazada por Aída cuando se entera de que su hija Lorena frecuenta a "Doble Ka", un joven de piel negra. Aída termina por afirmar que es un "muerto de hambre que ha venido a robarles" (2x16). En ese capítulo, son varios los estereotipos negativos asociados a la inmigración africana escenificados. Primero, aparece el vendedor de música y películas piratas en el "top manta". Mauricio, que acepta llevarse un CD a cambio de su silencio, critica hipócritamente el peligro que supone la piratería para los artistas nacionales. Eugenia abunda en este sentido, convirtiéndose en la portavoz de una retórica populista según la cual los inmigrantes hacen bajar el coste de la mano de obra y les quitan el trabajo a los españoles cualificados.

Además, el joven "Doble Ka", que sale con Lorena, es continuamente sospechoso de robo. "Doble Ka" suscita la desconfianza de los vecinos del barrio, incluyendo aquellos que sostienen discursos antirracistas. Así, Chema, el tendero filántropo, recuerda la tradición inmigrante de los propios españoles, por ejemplo hacia Alemania, y le pide sin embargo que enseñe las manos al entrar en su tienda. Finalmente, es evocado el estereotipo de la hipersexualidad de los hombres negros. Aída se escandaliza al ver a "Doble Ka" tocarle el culo a su hija. En cuanto a Macu, la sobrina de Mauricio, ésta se queda embarazada tras un encuentro con David, un chico negro. Cuando su tío descubre que el bebé es negro, rehúsa reconocer su vínculo familiar; Luisma, igualmente, se queda pasmado cuando descubre que no es el padre del niño (5x74). Por último, en otro capítulo, Aída tiene una aventura de una noche con un hombre de raza negra, el mejor indicado, según el consejo de su amiga Paz, para satisfacer los deseos de una mujer blanca (4x45).

En su obra La matrice de la race, Elsa Dorlin (2006) muestra como la economía de las colonias esclavistas contribuyó a producir una ideología racista apoyándose en un discurso destinado a mantener la jerarquía entre raza, clase y género. Es de este imaginario del que se extraen los estereotipos asociados al hombre negro. "Las consideraciones médicas permiten instaurar una frontera físico-patológica entre los esclavos y las mujeres de los colonos" (Dorlin, 2006: 257). Según esta misma retórica, "los negros son salvajes, brutos y analfabetos" (Fanon, 1952: 54). En la serie, se ocupan de trabajos menores o cometen pequeños hurtos 0 , al menos, son sospechosos de ello. Además, no asumen las consecuencias de su sexualidad (como atestigua el estereotipo verbal sobre dicha hipersexualidad de los hombres negros 
en el episodio 47 de la cuarta temporada) y sus cualidades físicas, puestas de manifiesto por la temática de la sexualidad, dejan a cambio una madre soltera. La afasia y la pasividad de "Doble K" ante la violencia racista, así como la ausencia de David, el padre del hijo de Macu, son, por tanto, portadoras de un repertorio parecido al del "tirailleur" (tirador ${ }^{3}$ ) tal y como ha sido identificado en el imaginario colectivo occidental por Pap Ndiaye: "cada característica tiene una doble cara: la infancia es asociada a la inocencia y a la irresponsabilidad, la indolencia a lo inofensivo y a la pereza; las cualidades físicas, a victorias deportivas y a la violencia. La ambivalencia del tirador permite un desplazamiento sobre el eje del repertorio del salvaje cuando las circunstancias así lo requieren" (Ndiaye, 2008: 217).

El tercer grupo de inmigrantes en nuestra tipología corresponde a los asiáticos. Éstos no aparecen más que de manera ocasional en la serie y nunca ocupan papeles protagónicos. Por ejemplo, Mauricio es condenado a cumplir horas de trabajo comunitario en un centro de ayuda a inmigrantes y allí insulta a uno de ellos dirigiéndose a él como "tú, la Gran Muralla" (8x148).

Los otros dos personajes de origen asiático identificados en nuestro corpus son dos hombres más. Ambos encarnan el estereotipo del trabajador, sonriente, paciente y resignado. Se caracterizan asimismo por su escaso dominio del español. Es el caso del nuevo proveedor del tendero Chema, que no comprende una sola palabra cuando se dirigen a él pero sonríe y escucha con paciencia, al tiempo que hace aumentar el nerviosismo de Chema: "Vamos a ver, yo no tengo nada en contra de los chinos, incluso he leído a Confucio. Lo que pasa es que el pedido está mal, falta el arroz, las bolsas... ¿cuál es el problema?, ¿es que hablo en chino?, ¿hay alguien aquí que hable español?, ¿alguien que diferencie entre hierro y hielo?" (6x94).

Por último, cuando Aída decide acoger en su casa a un estudiante norteamericano, ella y su familia imaginan que recibirán a una especie de "cowboy" en su hogar. Cuál no será su sorpresa cuando se encuentran con Bobby Tang, un joven americano de origen -y rasgos- asiáticos. Silencioso y sonriente, se convertirá en el juguete del barrio y sufrirá sin protestar toda clase de humillaciones. La familia García le roba y le obliga a hacer las tareas domésticas. Luisma arroja a propósito un objeto al suelo para que él lo recoja: “¡no sé cómo he podido vivir tanto tiempo 
sin un chino!", exclama. Tang, por supuesto, sufre tanto violencia verbal (le llaman "Tamagotchi") como física, llegando a ser golpeado (4x47). En ese episodio, los estereotipos evocados son múltiples, con simplificaciones que les asocian a la venta ambulante, a los masajes, a las artes marciales. Además, se burlan de la pronunciación de Tang, de su estatura y del color de su piel, todo, para subrayar que a los ojos occidentales en su comunidad son todos "intercambiables". 0bviamente, los personajes "vistos como" asiáticos no escapan a unas asignaciones etno-raciales estereotipadas. Como confirma Joaquín Beltrán Antolín (2008: 32), “Los distintos países y regiones que conforman Asia Oriental constituyen lugares exóticos para los occidentales. (...) La zona está cargada en su significación de dominantes y fuertes estereotipos, pre-concepciones y pre-juicios como, por ejemplo, la sumisión de las mujeres, el refinamiento de las torturas y crueldad, la falta de expresividad, etc."

Continuando con la tipología establecida, en cuarto lugar se encuentran los inmigrantes procedentes de Europa del Este, de los que podemos destacar que son eminentemente asociados al ámbito delictivo. Luisma y Macu confunden a dos hombres (identificados como europeos del este por su acento) con ladrones. Retratados como fuertes y amenazadores, el malentendido nos deja entrever que se trata de delincuentes. "Esta gente no sabe más que robar" comenta, por su parte, Luisma (5x76). En realidad, los dos personajes objeto del equívoco no son ladrones, pero de hecho sí emprenderán la huida al oír sirenas de policía, dando a entender que no tienen la documentación en regla o que tienen otros delitos que esconder. $\mathrm{Su}$ designación también resulta significativa. La abuela, Eugenia, remite con su generalización a épocas pasadas y afirma que son rusos, mientras que Luisma llama a uno de ellos "Stoichkov", nombre de un futbolista búlgaro.

Asimismo, en esta categoría podemos encuadrar a otros tres personajes más: se trata de unos jugadores de póker a los que Luisma y su amigo Barajas deben dinero. Aparecen caracterizados como extremadamente peligrosos, e incluso portan armas. Retratados como miembros de una mafia, obligan a los dos amigos a jugar a la ruleta rusa -otro tópico- mostrándose muy amenazantes (7x118).

ICONO14 | Año 2014 Volumen $12 N^{\circ} 1$ | ISSN: 1697-8293 | DOI: ri14.v12i1.566 
Las mujeres de esta categoría están prácticamente ausentes del corpus, solamente son evocadas a través de nombres eslavos cuando Mauricio hace referencia a unas prostitutas. Así, los estereotipos vinculados a la Europa oriental recogen el testigo de un imaginario populista que ve al bloque del Este como una amenaza: "Europa del Este es un monstruo que supone una «amenaza» imaginaria a la supervivencia del Oeste", en palabras de Daniel Esparza (2009: 58). Este autor subraya que esta retórica corresponde a Rusia y Europa del Este, a excepción de la triada Praga-VienaBudapest. Ésta percepción se ancla en la propaganda anti-comunista de la Guerra Fría y relaciona la caída del Muro de Berlín con una ola migratoria sobre el Oeste conformada por una población inmersa en la miseria y la criminalidad.

Finalmente, la última categoría de inmigrantes que aparece en el corpus es la de los personajes "vistos como" árabes. Emergen tardíamente, sólo a partir de la séptima temporada. El estereotipo evocado es el propio de los imaginarios mediáticos post 11-S. Durante el transcurso de un vuelo Madrid-París, Luisma y Mauricio creen que dos pasajeros son terroristas islámicos. Ambos personajes viajan con sendas mochilas, lo que levanta las sospechas de los dos amigos. Cuando intentan advertir al personaje de Paz, que es azafata en ese avión, ella misma se burla del estereotipo: " $\mathrm{S}$ í, claro!, todos los árabes son terroristas y todos los chinos saben kung-fu”, exclama con ironía (7x119). Realmente, los dos pasajeros no son más que turistas que portan en las mochilas simples e inocentes "souvenirs" de Madrid.

El episodio, pues, se mofa, jugando con la amalgama que a menudo se crea entre país de origen, religión y fanatismo: los dos amigos presentan una actitud xenófoba estigmatizando a los dos turistas basándose en su apariencia. En su estudio sobre los imaginarios mediáticos del Islam y el mundo árabe en Europa, Paul Balta (1994) observaba cuatro estereotipos recurrentes: el terrorista (desde los fedayines palestinos a los secuestradores que surgieron tras el estallido del conflicto libanés en 1975); el pobre trabajador inmigrante, poco cualificado; el rico emir del Golfo, surgido del primer "boom" petrolero en 1973; el integrista fanático, aparecido tras la victoria de Jomeini en 1979 en Irán, que se define con la guerra de Afganistán y se confirma con la ascensión del islamismo en diversos países. La escenificación de estos dos pasajeros muestra el predominio, al menos en la serie, de la esterotipación más cercana al terrorismo ligado al integrismo fundamentalista. 
Precisamente, el episodio titulado "Con ratón salvaje" (8x148) introduce un estereotipo más en el que, por la singularidad de sus rasgos, merece la pena detenerse. Se trata de una mujer que porta un velo, figura asociada comúnmente en el imaginario occidental al integrismo religioso. En dicho capítulo, Mauricio se ve obligado a cumplir horas de trabajo en beneficio de la comunidad en un centro de ayuda a inmigrantes. Cuando se cruza con una mujer con velo, ésta no escapa del tratamiento burlón que Mauricio acostumbra a exhibir: éste se saca su pañuelo del bolsillo poniéndoselo sobre la cabeza a la vez que emite estridentes alaridos para simular los gritos bereberes tradicionales. Frente a esta agresión, la mujer del velo no responde, únicamente sale corriendo. En dicha escena, no vemos su rostro, la mujer queda sin identificar. Así, su invisibilidad es reforzada por su posición en los extremos del campo de cámara: se encuentra en los márgenes y sólo se la entreve, no es más que intuida. De este modo, si bien el propio tono humorístico de la serie permitiría denunciar un estereotipo a través de una presentación crítica del personaje de Mauricio, en realidad la representación hegemónica de la mujer con velo se acaba reforzando implícitamente. Esta mujer no tiene acceso a un discurso, ni siquiera a la visibilidad. Literalmente se encuentra en los márgenes. Es más, frente a la agresión de la que Mauricio la hace objeto, se le priva de la capacidad de respuesta y debe huir, haciéndose precisamente invisible en el encuadre. Comprendemos aquí que las asignaciones etno-raciales se cruzan con las propias del género: esta mujer no tiene acceso al espacio público en las mismas condiciones que un hombre (se apresura a salir corriendo) ni tampoco en comparación con otras mujeres (las españolas del corpus tienen derecho de respuesta frente a las agresiones). En cambio, este personaje es vulnerable, al verse enmarcada en una situación de inferioridad jerárquica pese a que la igualdad entre hombres y mujeres es un derecho en España. Su sumisión da a entender que ella encarna a una víctima de un patriarcado exótico alienante (Guénif-Souilamas \& Macé, 2004), hasta tal punto que se le niega el acceso al discurso, quedando silente.

A la vista de todo lo anterior, se hace patente, pues, que el estereotipo es un régimen de presentación recurrente en la telecomedia Aída. El personaje de Mauricio posibilita claramente, amparado por el humor, la aparición de tópicos y prejuicios racistas. Como él mismo resume: “ ¡No me gustan los inmigrantes!, los rumanos roban, los negros huelen mal, los chinos son raros y los sudamericanos 
son muy feos" (8x148). Pero, más allá de la risa, los estereotipos empleados de forma recurrente en la serie pueden llegar a resultar chocantes. La escenificación de comentarios racistas ha creado ciertas reacciones, que han quedado reflejadas en la esfera de Internet ${ }^{4}$. Sin embargo, un artefacto retórico bien engrasado apoya la permanencia de ese régimen de representación. Las instancias productoras, apuntaladas también por las opiniones vertidas públicamente por los actores, subrayan que Aída funciona bajo el registro de la parodia: encontramos al fascista, al inmigrante, a la persona mayor amargada, al drogadicto arrepentido e idiota, al joven delincuente, al idealista, al homosexual, a la prostituta, a la madre soltera... El dispositivo enunciativo que permite vehicular esos estereotipos no es otro que el humor. La caracterización negativa de los personajes (Mauricio es fascista, Aída es alcohólica, Lorena es vulgar) y el tono cómico justifican y normalizan el uso de estereotipos racistas. Al igual que las ambigüedades de la enunciación satírica analizadas por Marlène Coulomb-Gully en Les Guignols de l'Info (el original francés de lo que fueron Las Noticias del Guiñol, creación de Canal Plus), podemos entonces interrogarnos aquí sobre "la suspensión ética" (Coulomb-Gully, 2012: 214) que el humor parece autorizar.

\section{Discusión}

\subsection{Las fronteras de una ficción nacional}

La representación televisiva de las cinco categorías de inmigrantes identificadas en el corpus se caracteriza por el recurso a los estereotipos. Estos se corresponden con tres perfiles migratorios: la mano de obra, la inmigración ilegal -a veces asociada a la delincuencia- y finalmente la inmigración por matrimonio. Pero, más allá de los estereotipos recurrentes, la perspectiva diacrónica adoptada en este análisis arroja luz sobre las modalidades de contribución de la televisión a la construcción de un "imaginario nacional" español. En su obra sobre esta cuestión, Benedict Anderson articula imaginarios, técnicas y realidad para mostrar que las colectividades nacionales son "comunidades imaginadas". Si el distingo con el que se opera entre lo real y lo imaginario puede a primera vista parecer artificial, el concepto que desarrolla aclara, sin embargo, el papel de la producción televisiva nacional en esa construcción de la propia comunidad. El imaginario y la institu- 
ción se sostienen en efecto mutuamente, como nos recuerda Cornelius Castoriadis: “lo simbólico comporta, casi siempre, un componente 'racional-real': aquello que representa lo real, o lo que es indispensable para pensarlo, o para hacerlo efecto. Pero este componente está tejido inextricablemente con el componente imaginario efectivo." (Castoriadis, 1975: 192) Consideramos al respecto que el régimen de representación simbólico que constituye el estereotipo contribuye a la producción de una comunidad nacional a través de un programa de ficción televisiva. Esta afirmación no implica una perspectiva determinista del medio televisivo sino que reivindicamos una crítica constructivista de las relaciones entre producción, usuarios y contenidos televisivos. Como nos recuerda Enric Castelló, “la nación no se constituye exclusivamente en el sentido de una comunidad comunicacional (...). La televisión forma parte de un entorno social complejo en el cual otras instituciones importantes desempeñan el papel de 'constructor de la nación'." (Castelló, 2009: 306)

En nuestra medición, a lo largo de las ocho primeras temporadas de Aida, de la evolución de la intensidad de los estereotipos etnoraciales, observamos cómo una comunidad escenificada a la escala de un barrio supuestamente prototípico de la España media permite la producción y el mantenimiento de una unidad nacional. El mecanismo que caracteriza a los estereotipos identificados más arriba es el de la designación. Nombrando, a través del insulto, de la burla y de los roles narrativos la singularidad de los personajes vistos como inmigrantes, asistimos a la elaboración de un "dispositivo coherente, escenario de la inteligibilidad propia de una nación" (Le Blanc, 2010: 17). El objetivo es delimitar las fronteras de la comunidad nacional según un esquema binario estructurado alrededor del eje dentro/fuera. Una investigación anterior sobre las figuras de la diversidad en la serie Física $o$ química demostraba cómo los regímenes de representación televisivos reproducen a los inmigrantes como figuras del extranjero (Biscarrat, 2012). “El nacional crea la ficción del extranjero para hacer olvidar él mismo que se trata de una ficción. Esto es así porque lo nacional es una ficción, una amalgama de convenciones que no reposan sobre evidencia alguna (de suelo, de sangre, etc.), que constituyen un género performativo íntegramente encapsulado en el hecho de engendrar al extranjero como su otro." (Le Blanc, 2010: 53).

ICONO14 | Año 2014 Volumen $12 \mathrm{~N}^{\circ} 1$ | ISSN: 1697-8293 | DOI: ri14.v12i1.566 
La perspectiva diacrónica facilita la revelación de mecanismos de designación del extranjero. De este modo, a lo largo de las temporadas analizadas, se dibuja, en efecto, una clara evolución. En las primeras temporadas de Aída asistimos a una situación aparentemente paradójica. Por un lado, los inmigrantes como personajes son globalmente invisibilizados; por otro lado, el tema de la inmigración se pone de manifiesto repetidamente de manera explícita. Los personajes vistos como inmigrantes no tienen acceso a los mismos roles narrativos que los personajes vistos como españoles. Es más, a menudo, apenas se les ve y ni siquiera toman parte en los diálogos. Así, adivinamos en ocasiones su presencia como fuerza de trabajo: en el bar Reinols, donde se encuentran en segundo plano, sirviendo tras la barra. La cámara en ningún momento los enfoca directamente ni participan en la trama narrativa. Cuando su presencia se hace más visible no es porque sean incluidos plenamente en la intriga sino para operar como elementos catalizadores de las relaciones entre protagonistas. Por ejemplo, es el caso ya comentado de un vendedor ambulante africano que ofrece sus artículos en la terraza del bar. Mauricio le recrimina por su actividad, quejándose del daño que la piratería causa a los artistas nacionales. Aquí el inmigrante es filmado de perfil, apenas entra en el encuadre, mientras que Mauricio aparece de frente. Para salir airoso de la situación, el vendedor le ofrece un CD y Mauricio le deja marcharse. Así, entra en escena Chema, que se indigna por el comportamiento de Mauricio, quien replica: "el primer mundo es así, si no le gusta que se vuelva a la selva". También Aída participa y, enfadada, tilda a Mauricio de animal y de racista saliendo en defensa del vendedor ambulante. Mauricio, por su parte, niega ser racista. La abuela, Eugenia, se añade y hace un comentario sobre el impacto negativo de la inmigración para el mercado de trabajo nacional: según su opinión, los inmigrantes hacen bajar el coste de la mano de obra y quitan empleo a españoles cualificados. Chema subraya que España siempre ha sido tierra de emigrantes y pone el ejemplo de los españoles que se marcharon en su día a Alemania. Aída se pregunta sobre la importancia de las diferencias de color y afirma que cuando las personas tienen hambre son todas iguales y concluye: “os guste o no, esta gente vive aquí, lo que debemos hacer es ayudarles a integrarse" (2x16).

Como vemos, el inmigrante aquí no es más que la excusa para establecer un debate sobre la inmigración. Aún siendo el primer implicado, el personaje del vendedor ambulante no tiene derecho a tomar la palabra. 
Esta secuencia es emblemática del tratamiento de los inmigrantes durante las primeras temporadas de la serie: el tema de la inmigración se pone de manifiesto pero no así los personajes que la encarnan, que son sistemáticamente rechazados. Así, el vendedor ambulante es repelido; “Doble Ka", el chico que sale con Lorena, no es aceptado por la familia, el vecindario $\mathrm{y}$, finalmente, por la propia Lorena (2x16). En cuanto a Cristal, la joven venezolana de la que se encapricha Mauricio, acaba siendo vivamente rechazada en el punto culminante de un auténtico vodevil: Cristal será objeto de múltiples humillaciones y acaba prácticamente desnuda frente a un cura inconcebiblemente lascivo porque Lorena y Paz se encargan de estropear su vestido de novia y el grupo entero hace piña contra ella (1x13). En dicha escena, ella tampoco disfruta del derecho a tomar la palabra, ni nadie le pide explicaciones. Finalmente, Cristal debe salir huyendo sin que ni siquiera los otros adviertan su marcha. No sólo es apartada, sino que se vuelve literalmente invisible a ojos de los demás.

Podemos, pues, decir que los estereotipos de rango 0 (mera aparición), 1 (representación orientada) y 2 (estereotipos verbales) se dan mayoritariamente en las primeras etapas de la serie. La representación de los inmigrantes se basa en su rechazo. Los ejemplos aquí evocados subrayan el mecanismo de exclusión de los inmigrantes del campo discursivo de la comunidad. Están ausentes del discurso y son eclipsados en la imagen a causa de un rechazo por el grupo visto como "español" 0 porque no participan en la trama narrativa (especialmente en el caso del nivel 0). Desde un punto de vista discursivo, la construcción televisiva de una comunidad nacional pasa por la estigmatización de los inmigrantes, a través de estereotipos verbales y de insultos, pero igualmente a través de limitarles el uso de la palabra. "La frontera creada por el poder lingüístico está destinada a arrogarse el derecho a la doble designación del otro como extranjero o del extranjero como otro." (Le Blanc, 2010: 40) Aquí, el imaginario televisivo de la comunidad es el de la exclusión de los extranjeros. Éstos son mantenidos a distancia a través de "diferencias asimilables a regímenes de alteridad" (Le Blanc, 2010: 26). A través de los estereotipos, se caracteriza a los inmigrantes con rasgos que tienen valor de definición y que justifican su exclusión.

En estas primeras entregas de Aída, las fronteras de la comunidad son, por tanto, delimitadas por el rechazo a los inmigrantes. Construido sobre la exclusión, 
este régimen de representación, se inscribe en un contexto nacional de importantes flujos migratorios entrantes, un fenómeno que contrasta con la tradición emigrante de la población española (y a la que las circunstancias actuales están obligando a volver en el presente). A lo largo de las temporadas, el análisis diacrónico revela sin embargo una clara evolución del tratamiento televisivo de la figura del inmigrante/extranjero. La publicación en aquellos días de recomendaciones para sensibilizar a los profesionales de los medios muestra la voluntad política de una consideración más atenta del fenómeno migratorio en las representaciones mediáticas. Aparecida en 2008, bajo el gobierno socialista de José Luís Rodríguez Zapatero, dicha guía aporta una serie de sugerencias destinadas a reducir la discriminación y a mejorar la imagen mediática de los inmigrantes (Sendín Gutiérrez \& Izquierdo Iranzo, 2008). Esta reflexión sobre la consideración televisiva de los inmigrantes parece encontrar un eco favorable entre los guionistas de Aída, o cuanto menos, se corresponde con el rumbo que toma la serie. En efecto, se observa un proceso de complejización y de inclusión narrativa de la figura del inmigrante a lo largo de los siguientes capítulos. Si los niveles 0 a 2 (de lo implícito a la estereotipación verbal) están siempre presentes, el análisis subraya el aumento de una representación de nivel 3, es decir, a partir de este momento los personajes inmigrantes desempeñan un rol en la trama narrativa.

En una investigación anterior sobre la ficción televisiva española, Xavier Ruiz Collantes y su equipo identificaron tres roles narrativos principales asociados a los inmigrantes: el seductor/manipulador, el que quiere ayudar pero cuya acción resulta ineficaz; y el justiciero de gran corazón (Ruiz Collantes, 2006). Encontramos, por nuestra parte, estas mismas narraciones prototípicas en nuestro corpus. Del primer tipo, cuando Cristal seduce a Mauricio para un matrimonio de conveniencia (1x13) o del segundo, cuando Machu Pichu ayuda a Lorena a prepararse para concursar en el festival de Eurovisión. Macu destaca entonces la inutilidad de su acción: "Él ni siquiera puede ir a Eurovisión, ¡es extracomunitario!" (8x148). Finalmente, como ejemplo del tercer caso, Machu Pichu denuncia valientemente una estratagema de Mauricio, que no duda en enriquecerse a costa de sus vecinos cuando las autoridades intentan hacer desaparecer el barrio para construir una autopista $(6 \times 100)$. 


\subsection{Un personaje con recorrido: las dos caras del inmigrante a través de la exclusión como Machu Pichu y la integración como Osvaldo}

Una de las revelaciones del enfoque diacrónico empleado es la interesante evolución del principal personaje de origen inmigrante de la serie, cuya mayor complejidad la denota algo tan significativo como los dos nombres por los que es conocido y designado: Machu Pichu-0svaldo.

$\mathrm{Si}$, como decíamos, en las primeras temporadas, el inmigrante es en el mejor de los casos un catalizador del relato, observamos, a lo largo de los episodios y, sobre todo de la mano del camarero latino, un aumento de su rol narrativo. Así, una nueva trama empieza a dibujarse, la de la emancipación. Machu Pichu ejerce repetidas veces su resistencia frente a su jefe Mauricio, primero con la ayuda de los habitantes del barrio, y ya luego de manera autónoma. Chema es el primero en querer ayudarle. Él es, en efecto, una figura sensible a las dificultades de inserción de los inmigrantes, volcado por completo durante años en una ONG local. Para denunciar el racismo y la explotación que Mauricio inflige sobre sus empleados, Chema no duda en encadenarse a las rejas de su bar (3×36). Con todo, progresivamente Machu Pichu se va a defender él mismo de los ataques de su patrón. Cuando Mauricio muestra su intención de despedirle, el camarero latinoamericano se rebela y le reprocha a su jefe su ingratitud, le dice que es un fascista y que trata a sus empleados como animales. Machu Pichu le habla en esta ocasión de igual a igual, a diferencia de la habitual sumisión que suele mostrar: recordemos que llama a su jefe Licenciado, aunque este no tiene titulación universitaria (4x68). No duda incluso en cuestionar las decisiones de Mauricio: le pregunta por qué él no puede utilizar el ascensor para subir un colchón a casa de Eugenia y se niega a seducirla, tal y como le exige Mauricio, “ ¡es doña Eugenia!, antes prefiero comer testículos de jabalí" (6x88). Es este un eje de resistencia que se desarrolla entre el camarero explotado y su jefe, a veces en escenas de conflicto: Machu Pichu elige en un momento dado entre la comunidad y Mauricio, decantándose por la primera al decidir denunciar la estratagema del dueño del bar para enriquecerse a costa de los vecinos $(6 \times 100)$.

ICONO14 | Año 2014 Volumen $12 N^{\circ} 1$ | ISSN: 1697-8293 | DOI: ri14.v12i1.566 
Esta decisión marca un cambio de rumbo. Generalmente, cuando Machu Pichu participa en la intriga, e incluso cuando su papel resulta importante, es en realidad utilizado por los demás personajes. Por ejemplo, estropea una estatua (8x148) o se hace pasar por gigoló (6x88) para servir a los intereses de Mauricio. Pero, hacia el episodio 100, se observa una postura autónoma y valiente por su parte: el personaje inmigrante desempeña un rol fundamental en el relato. Y, por otro lado, se consolida y adquiere el estatus de personaje por entero, en el sentido de que esta vez él es un protagonista que modifica de manera autónoma el curso de la narración. Su decisión de denunciar a Mauricio va, sin embargo, en contra de sus intereses inmediatos, pues se arriesga a perder su empleo. El mecanismo de resistencia que se ha ido forjando culmina aquí con la consecución de la autonomía por parte de la figura del inmigrante, simbolizada por una bofetada que Machu Pichu propina a Mauricio en un momento dado.

En los siguientes capítulos, Machu Pichu aparece cada vez más integrado en la comunidad de Esperanza Sur. De este modo, participa en un concurso de rap y acaba batiéndose contra Jonathan, el hijo de Aída, al que vence con solidez, ganando un cheque de 100 euros. Impresionado por su actuación, Jonathan le invita a otro campeonato de rap, pero el camarero le dice que su siguiente día libre no será hasta dentro de tres meses. Mauricio le hace entonces el favor de permitirle librar: “Ve, anda, para una vez que tienes amigos españoles... pero, ojo, ¡no bailes! Tu Dios podría darse cuenta y empezaría a llover" (6x109). Mediante este concurso, Osvaldo se gana el reconocimiento de la comunidad y traba relaciones de amistad con Macu y Jonathan. Más adelante, se apunta junto a otros vecinos del barrio a un torneo de batalla láser (8x153). La progresiva autonomización e integración en la comunidad parecen, pues, caracterizar el régimen de representación de este personaje inmigrante.

Un examen más atento matiza, en cualquier caso, estas constataciones. Cuando Machu Pichu regenta su propio negocio, una tienda de comestibles en el barrio, continua no obstante manteniendo una relación de servidumbre con Mauricio. Por ejemplo, ayuda a su antiguo jefe a seducir a una de sus conquistas, ocupándose de todas sus necesidades: “le compré preservativos, cambié las sábanas y, no tiene que preocuparse, su madre duerme en mi casa esta noche" (8x128). Además, los estereo- 
tipos verbales y los insultos continúan apareciendo de forma recurrente. Osvaldo es constantemente designado como "el indio" (7x114), cuando no por otros calificativos despectivos tales como "Mowgli" (6x88) o "buen chico" (7x115), como si se tratase de un animal doméstico al que se está felicitando. Este recurso al insulto resulta muy característico: pese a que el inmigrante esté muy integrado en la comunidad, de esta manera se le vuelve a distinguir, a caracterizar en negativo. Se trata de un rito de interpelación, un marcador que busca la estigmatización (Butler, 2008). Si bien se ha convertido en un miembro del grupo, Machu Pichu no es enteramente parte de él. Desempeña un papel fronterizo, "ni totalmente dentro, ni totalmente fuera" (Le Blanc, 2010: 43). Él ocupa en realidad un espacio intersticial y residual: el concurso de rap no está destinado a todos, ya que busca favorecer la integración. Machu Pichu puede, ciertamente, participar en la batalla láser, pero por circunstancias de la trama acaba casi desnudo después de haber sido cubierto de basura. “El extranjero no es un héroe de la adversidad radical sino un merodeador que, habiendo traspasado ciertas fronteras, es rechazado y conducido a otras fronteras, situadas de hecho en espacios intermedios, entre dentro y fuera." (Le Blanc, 2010: 43)

Dicha ambigüedad resultará particularmente patente en un capítulo situado en Nochebuena. Mauricio anula repentinamente el descanso concedido a su empleado. Machu Pichu tendrá entonces que servir la cena de la familia García en el bar, en lugar de celebrar la Nochebuena con su familia. Ante su amargura, Mauricio permite a Osvaldo finalmente compartir la cena y manda a Néstor, el otro camarero, encargarse del servicio (8x142). Privado de una Navidad con su familia, 0svaldo celebra la Nochebuena con los habitantes del barrio. Esta escena simboliza su integración en la comunidad. Pero esta inclusión tiene un coste: la ruptura con los lazos familiares y con sus orígenes. La ideología que subyace en esta secuencia condiciona, pues, la integración del extranjero en la comunidad, que ha de pasar por la neutralización de cualquier otro vínculo o cultura: una lectura de la diferencia totalmente imposible que devuelve siempre al inmigrante a su alteridad. Aunque, integrado en la comunidad, el inmigrante constituye una figura diferente, de extranjero. La distinción que se hace entre él y el grupo hace existir a la comunidad, de la que él es la frontera. Es más, las consecuencias de la inclusión de Osvaldo recaen directamente en otro personaje inmigrante, Néstor, que es el que acaba ocupando su lugar, reforzando la diferencia. 
Hay que aportar un último matiz al análisis del proceso de emancipación del inmigrante en la serie. Se comprueba, en efecto, que éste, encarnado por Machu Pichu, no consigue nunca una igualdad efectiva frente a los otros personajes. Si, ocasionalmente, toma decisiones de manera autónoma -por ejemplo, cuando lleva a su jefe a un club de salsa para animarlo (7x114)-, parece que el personaje del inmigrante se caracteriza más globalmente por su heteronomía. Machu Pichu imita, así, el racismo de su patrón y su forma de tratar a los trabajadores. La emprende con Luisma, ocasionalmente empleado para hacer publicidad del bar: “iPero qué imbécil!, ¡Ha olvidado los folletos!, ¡español de mierda! No sirves más que para servir paella a los alemanes" (6×107). El recurso humorístico aquí utilizado es la inversión: el camarero sudamericano reproduce las asignaciones etno-raciales de las que él mismo es objeto. Su incapacidad para presentarse como una figura autónoma se trasluce en el momento en el que adquiere un poco de poder. Cuando Mauricio se da un golpe en la cabeza y pierde la memoria, Machu Pichu invierte los roles y aprovecha para tomar el lugar de su jefe. Pero resulta incapaz de dirigir el bar sin recurrir a las mismas prácticas tiránicas de su predecesor, obligando a Mauricio a llamarle "doctor Osvaldo Wenceslao" y mostrándose autoritario en todo momento: “'Cuatro horas para fregar los vasos!, ¿cuál es el problema?, ¿es que los españoles sólo se dan prisa si les persigue un toro?" (6x94). Cornélius Castoriadis define la autonomía como "instauración de otra relación entre el discurso del 0tro y el discurso del sujeto" (Castoriadis, 1975: 175). Así, si Machu Pichu desempeña aquí un papel más destacado en la jerarquía social, la relación que le une a Mauricio reproduce su propia condición de camarero inmigrante. Sus decisiones y motivaciones están inspiradas por los otros protagonistas. La autonomía de la que intenta hacer gala es, pues, relativa. Sobre todo, el personaje del inmigrante se caracteriza aquí por su heteronomía, tanto individual como social. No puede deshacerse de la relación de alteridad que mantiene con la comunidad española, recordándonos así que la figura del extranjero es una construcción eminentemente social.

Al término de la medición diacrónica de la intensidad de la estereotipación de los inmigrantes en la serie, podemos afirmar que se dibuja una evolución a lo largo de las temporadas, pero que esta evolución no es estrictamente lineal. Si bien se tiende a una mejora de la imagen de los inmigrantes gracias a un proceso de complejización narrativa y de inclusión de esta categoría de personajes en el relato, 
el régimen de representación televisiva renuncia, no obstante, a considerar a los personajes inmigrantes en calidad de iguales entre los personajes "españoles". La omnipresencia del estereotipo es en este sentido reveladora de la dificultad televisiva a la hora de abordar la temática de la inmigración sin recurrir a representaciones estandarizadas que refuerzan la re-producción de un imaginario nacional construido sobre la exclusión del 0tro.

\section{Conclusiones}

Si en los primeros episodios de Aída los inmigrantes resultan prácticamente invisibles, asistimos en el transcurso de las temporadas a un aumento de su presencia y a una multiplicación de las temáticas a las que se les asocia. Paradigmático de esta transformación, el personaje de Machu Pichu desempeña un papel muy secundario al inicio, hasta acabar cumpliendo progresivamente una función protagónica en la serie. Pero esta presencia acrecentada en la trama narrativa no debe llevarnos a pensar en una inclusión de los personajes inmigrantes en una comunidad multicultural e igualitaria. Se observa, en efecto, una omnipresencia de estereotipos en la telecomedia. Precisamente, el género de la serie es aquí un factor a tener en cuenta. Charo Lacalle destaca que el género televisivo aquí considerado, la comedia, se basa "en la necesidad genérica y estructural de construir personajes especificados" (Lacalle, 2008: 88). Este contrato de enunciación televisiva imbuye a los personajes de unos rasgos definitorios limitados y casi siempre caricaturescos.

Es así que, de manera casi perversa, la ficción televisiva contribuye a la producción y mantenimiento de estereotipos etno-raciales. Ha de jugar con la ambigüedad, moviéndose entre la clara estigmatización y la caracterización sintética de personajes con un fin humorístico. “QQué hace la televisión en este proceso de fabricación de estereotipos? Sin ninguna duda los produce. Conscientemente, para hacer reír, para ganar tiempo, para dar sentido, como en la publicidad o en la caricatura. Lo hace sin darse cuenta, en las ficciones o en los documentales, para situar el contexto. Pero sobre todo, se nos aparece incluso cuando la televisión declara su voluntad de luchar contra ellos, contribuyendo a propagar otros estereotipos." (Veyrat-Masson, 1989: 245) Esta es, pues, la dificultad que se revela tras el análisis propuesto. Cuando los inmigrantes parecen penetrar las fronteras de la

ICONO14 | Año 2014 Volumen $12 N^{\circ} 1$ | ISSN: 1697-8293 | DOI: ri14.v12i1.566 
comunidad, no llegan a encajar plenamente en ella y encarnan siempre una figura de alteridad, de extranjero. “[E]n la ficción televisiva la fusión del extranjero inmigrante con el cuerpo social de referencia constituye el horizonte de un paulatino proceso de acercamiento, desde la distancia entre el yo y el otro" (Lacalle, 2008: 29). Aunque la serie progresivamente haya matizado los clichés asociados a la inmigración, parece aún lejos de producir un discurso positivo y "normalizador" del fenómeno migratorio.

El dispositivo televisivo del programa de ficción Aída construye "los marcos de aquellas intervenciones humorísticas según las expectativas de la producción y de la recepción" (Quemener, 2007: 136). Previamente, hemos destacado que el tratamiento humorístico del personaje de Machu Pichu pudo conllevar una recepción contraria a la expectativa de connivencia de la audiencia a través del humor. Así, las huellas en foros digitales destacadas más arriba fomentan un debate en la esfera de internet sobre racismo -y sobre los límites del humor- que llegan incluso a rozar aspectos no resueltos de la historia contemporánea de España (en uno de los foros citados como ejemplo en la nota 4 se discute el hecho de que el dictador Francisco Franco fuera racista o no, lo que convierte en interesante la circunstancia de que se toque el tema del franquismo en estos debates virtuales). Una próxima etapa en esta investigación será, pues, el estudio de dichas huellas digitales, las cuales pertenecen a la experiencia de recepción en espacios colectivos favorables a la comunicación interpersonal (Granjon \& Le Foulgoc, 2010), lo que abre una nueva vía que completaría el análisis comenzado con la presente investigación.

\section{Notas}

[1] Traducción de las autoras, tanto en este caso como de aquí en adelante en las citas cuyo original está escrito en un idioma distinto del español.

[2] A partir de este caso y en lo sucesivo se emplea el sistema de identificación de capítulos a partir del número de la temporada seguido de " $\mathrm{x}$ " $\mathrm{y}$ terminando por el número del capítulo en el cómputo total de episodios.

[3] Tirailleur significa literalmente tirador de hostigamiento en francés. El término procede del período napoleónico, cuando era utilizado para designar a la infantería ligera entrenada para hostigar en la vanguardia de las principales columnas. Posteriormente, el término "tirailleurs" pasó a utilizarse

DOI: ri14.v12i1.566 | ISSN: 1697-8293 | Año 2014 Volumen 12 N 1 | ICONO14 
por la Armada Francesa como una designación de la infantería reclutada en los diferentes territorios coloniales franceses durante los siglos XIX y XX. Se recuerda comúnmente en este último sentido.

[4] Señalamos por ejemplo el foro http://www.formulatv.com/series/aida/foros/1308/1/razistas-de-mierda/ y la carta al director del periódico 20 minutos http://www.20minutos.es/carta/325291/0/ (fecha de consulta: 31/05/2012).

\section{Referencias}

Anderson, B. (1991). Imagined communities: reflections on the origin and spread of nationalism. London: Verso.

Balta, P. (1994). “Los medios y los malentendidos euroárabes”, en J. Bodas Barea y A. Dragoevich, (eds.), El Mundo Árabe y su imagen en los medios. (pp. 3044) Madrid: Comunica.

Beltrán Antolín, J. (2008). “Orientalismo, autoorientalismo e interculturalidad de Asia oriental", en A. Pedro San Ginés (ed.), Nuevas Perspectivas de Investigación Sobre Asia Pacífico, 2, edición aumentada. (pp. 31-47) Granada: Editorial Universidad de Granada.

Bertini, M.J. (2002). Femmes. Le pouvoir impossible. Paris: Pauvert.

Biscarrat, L. (2012). Figure du migrant et construction d'un imaginaire de l'étranger dans la fiction télévisuelle espagnole : étude de cas », informe de investigación Citoyennetés en couleurs : représentations médiatiques et pratiques culturelles urbaines dirigido Seok-Kyeong Hong-Mercier, Université de Bordeaux 3.

Butler, J. (2008). Le pouvoir des mots. Discours de haine et politique du performatif. Paris: Amsterdam.

Castelló, E. (2009). The nation as a political stage: A theoretical approach to television fiction and national identity. The international communication gazette, 71(4), 303-320. D0I: 10.1177/1748048509102183

Castoriadis, C. (1975). L'institution imaginaire de la société. Paris: Seuil.

Coulomb-Gully, M. (2012). Les Guignols de l'Info. Le 'genre' de la satire. Réseaux, 171(1), 189-216. DOI: 10.3917/res.171.0189

De Oliveira, J.P. (2011). Communication publique et prévention du sida : construction d'une politique publique en faveur des homosexuels masculins. En SFSIC (ed.). Actes des journées doctorales 2011. Bordeaux, 30-31 mars 2011. (pp. 97-104) Paris: Société Française des Sciences de l'Information et de la Communication. 
Dorlin, E. (2006). La matrice de la race. Généalogie sexuelle et coloniale de la nation française. Paris: La Découverte.

Dyer, R. (1997). The matter of whiteness. En R. Dyer (ed.) White: Essays on Race and Culture. (pp. 1-40) London: Routledge.

Esparza, D. (2009). Afronteras imaginadas y estereotipos: La creación de un monstruo llamado Europa del Este. Espacio, Tiempo y Forma, 2, 55-67.

Fanon, F. (1952). Peau noire, masques blancs. Paris: Seuil.

Foucault, M. (1976). Histoire de la sexualité. La volonté de savoir. Paris: Gallimard.

Galán, E. (2006). La representación de los inmigrantes en la ficción televisiva en España. Propuesta para un análisis de contenido. El Comisario y Hospital Central. Revista Latina de Comunicación Social, 61. Recuperado de http:// www.ull.es/publicaciones/latina/200608galan.htm

Granjon, F. \& Le Foulgoc, A. (2010). Les usages sociaux de l'actualité. L'expérience médiatique des publics internautes. Réseaux, 160/1, 225-253. DOI: $10.3917 /$ res.160.0225

Guénif-Souilamas, N. \& Macé, E. (2004). Les féministes et le garçon arabe. Paris: Éditions de l'Aube.

Hall, S. (2003). The whites of their eyes. Racist ideologies and the media. En G. Dines \& J.M. Humez (Eds.), Gender, Race and Class in Media. A text-reader (pp.89-93). London: Sage.

Hamilton Krieger, L. (2008). Un problème de catégories : stéréotypes et lutte contre les discriminations. Paris: French-American Foundation. Recuperado de http://www.frenchamerican.org/sites/default/files/documents/media_ reports/krieger_socialstereotypes_report_fr.pdf

Igartua Perosanz, J.J. et al. (2011). La imagen de la inmigración en la ficción televisiva de prime time. Un estudio de análisis de contenido. En F.J. García Castaño \& N. Kressova (Eds.), Actas del I Congreso Internacional sobre Migraciones en Andalucía (pp.219-228). Granada: Instituto de Migraciones. Igartua Perosanz, J.J. \& Muñiz, C. \& Cheng, L. (2005). La inmigración en la prensa española. Aportaciones empíricas y metodológicas desde la teoría del encuadre noticioso. Migraciones, 17, 143-181.

Igartua, J.J. et al. (2007). El tratamiento informativo de la inmigración en los medios de comunicación españoles. Un análisis de contenido desde la Teoría 
del Framing. Estudios sobre el Mensaje Periodístico, 13, 91-110.

Lacalle, C. (2008). El discurso televisivo sobre la inmigración. Ficción y construcción de identidad. Barcelona: Omega.

Le Blanc, G. (2010). Dedans, dehors. La condition d'étranger. Paris: Seuil. Macé, E. (2007). Des 'minorités visibles' aux néo-stéréotypes : les enjeux des régimes de monstration télévisuelle des différences ethnoraciales. Journal des anthropologues, número especial. Recuperado de http://jda.revues.org/2967 Memmi, A. (1985). Portrait du colonisé, portrait du colonisateur. Paris : Gallimard. Ndiaye, P. (2008). La condition noire. Essai sur une minorité française. Paris:

Calmann-Lévy.

Quemener, N. (2007). Quand le patriarche n'est plus là. Masculinités et humour dans les dispositifs de talk shows en France. Recherches en communication, 28, 135-146.

Ruiz Collantes, X. et al. (2006). La imagen pública de la inmigración en las series de televisión españolas. Política y Cultura, 26, 93-108.

Sendín Gutiérrez, J. \& Izquierdo Iranzo, P. (2008). Guía práctica para los profesionales de los Medios de Comunicación: Tratamiento Mediático de la Inmigración. Madrid: Ministerio de Trabajo y Asuntos Sociales Secretaría de Estado de Inmigración y Emigración Dirección General de Integración de los Inmigrantes.

Veyrat-Masson, I. (1989). Les stéréotypes nationaux et le rôle de la télévision. Hermès, 5/6, 237-253.

\section{Agradecimientos}

Agradecemos el Consejo Regional de Aquitania y la Maison des Sciences de l'Homme d'Aquitaine por su financiación de esta investigación dentro del programa "Citoyenneté en couleurs : représentations médiatiques et pratiques culturelles urbaines", dirigido por Seok-Kyeong Hong-Mercier, Universidad de Bordeaux 3. 